\title{
Gesturing Across Settler Divides in Marumpu Wangka! Kukatja Hand Talk
}

\author{
William Lempert \\ Assistant Professor, Department of Anthropology, Bowdoin College, \\ Brunswick, USA \\ wlempert@bowdoin.edu
}

\begin{abstract}
In 2014, the government of Western Australia proposed a plan to defund, and in effect close, about half of the nearly three hundred remote Aboriginal communities in the state. During this time, the author collaborated on a hand sign video project with five women Elders at the Kapululangu Women's Law and Culture Centre in Balgo, an Aboriginal community in the Great Sandy Desert. The author articulates why Marumpu Wangka! Kukatja Hand Talk-an unassuming and largely improvised video — struck a chord at this precarious moment for Aboriginal communities. The author argues that hand sign videos provide a rare mode of intercultural engagement that is simultaneously culturally specific and broadly relatable. In a mediascape in which most Australian viewers are inundated with visual tropes of Aboriginal communities as either suffering or mystical, representations of jovial gesture encourage understanding beyond these stereotypes by intimately engaging everyday community interaction. Referencing the supplemental eight-minute video throughout, the author (1) overviews the significance of hand sign systems in Aboriginal Australian communities, (2) describes the collaborative and improvised hand sign video production process, and (3) argues for the importance of visual representations that can transcend-even if modestly-settler/Indigenous divides during the current dangerous times for Aboriginal communities.
\end{abstract}

\section{Keywords}

gesture - hand signs - sign language - Aboriginal Australia - Indigenous media collaborative filmmaking

(C) WILLIAM LEMPERT, 2019| DOI:10.1163/23644583-00401015 | THIS IS AN OPEN ACCESS ARTICLE DISTRIBUTED UNDER THE TERMS OF THE CC-BY 4.O LICENSE. 


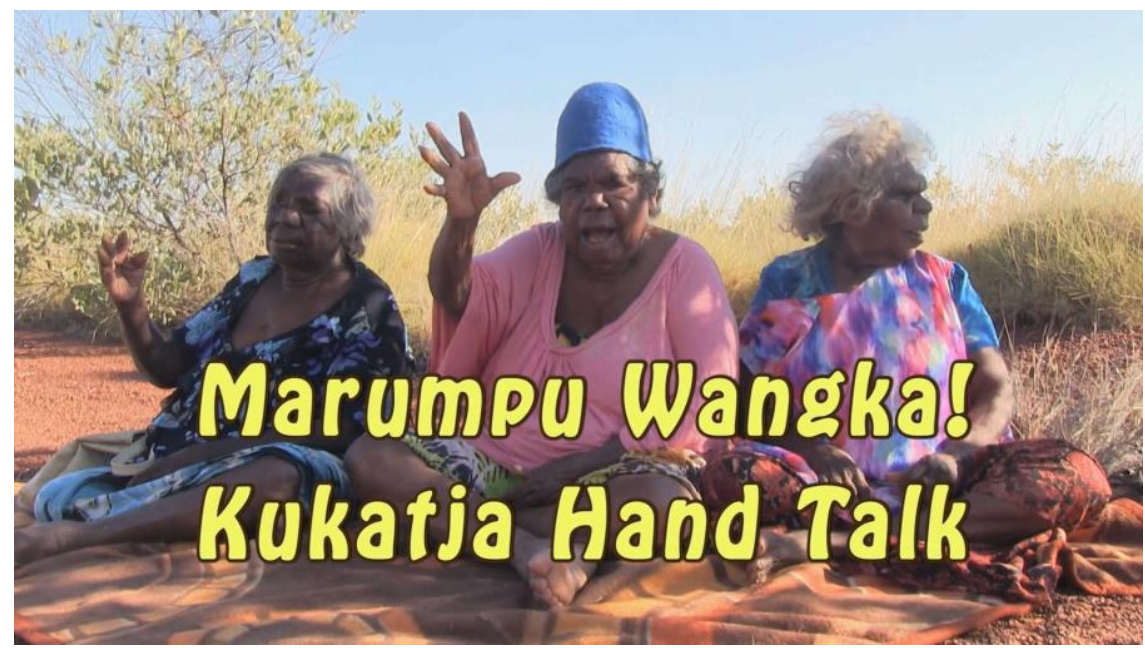

FEATURE Willi Lempert's article is based on the film 'Marumpu Wangka! Kukatja Hand Talk' which can be viewed here.

\section{Introduction*}

In November of 2014, the government of Western Australia proposed a plan to defund, and in effect close, about half of the nearly three hundred remote Aboriginal communities in the state. It was during this time that I was conducting ethnographic fieldwork in Wirrimanu (Balgo), an Aboriginal community in the Great Sandy Desert. During the height of this existential threat for Aboriginal communities, I collaborated on a video project about hand signs with Elders at the Kapululangu Women's Law and Culture Centre (Kapululangu). ${ }^{1}$ Filmed just down the road from Kapululangu, Marumpu Wangka! Kukatja Hand Talk (Marumpu Wangka) (Lempert and de Ishtar 2015) would go on to be widely distributed online and win film festival awards, as well as lead to other hand sign productions funded through National Indigenous Television (NITV) that we completed in subsequent years.

I articulate why this unassuming and largely improvised video struck a chord at this particularly precarious moment for Aboriginal communities. I argue that hand sign videos provide a rare mode of intercultural engagement that is simultaneously culturally specific and broadly relatable. Indeed, in a mediascape in which most Australian viewers are inundated with visual tropes of remote Aboriginal communities as either suffering or mystical,

Cultural warning: the following includes the names of individuals who are deceased.

I capitalize Elders as it is a norm in Balgo and signifies respect. 
representations of jovial gesture encourage understanding beyond these stereotypes by intimately engaging the everyday details of community interaction. Referencing the embedded eight-minute Marumpu Wangka video throughout, I (1) overview the significance of hand sign systems in Aboriginal Australian communities, (2) describe the collaborative and improvised hand sign video production process, and (3) argue for the importance of visual representations that can transcend-even if modestly - settler/Indigenous divides during the current dangerous times for Aboriginal communities.

\section{$2 \quad$ Aboriginal Hand Signs}

Hand signs are a bedrock of everyday communication in Aboriginal Australian communities. However, while many visitors likely notice a few of the most common signs, it is easy to miss the dozens of diverse hand signals being subtly exchanged during and outside of speech. Our films feature Kukatja hand signs, which is the most common system in Balgo. However, most of these signs are understood across the region, and many are understood across the continent. Indeed, these hand signs serve as a relative lingua franca, in comparison to the diverse array of spoken languages. Unlike primary sign languages, these alternative sign systems are not directed toward hearing impaired individuals, but rather, are used regularly by all community members.

Aboriginal hand signs have long fulfilled a variety of communicative roles within and between communities through hundreds of regularly exchanged gestures. Hand signs are essential for silent communication while hunting and are often used to exchange secrets (Kendon 1988, 1997), especially in the presence of cultural outsiders, where the contrast between the signed and spoken is a constant source of comedic commentary on power dynamics. They also serve various cultural purposes relating to speech avoidance around stepmothers and widows, and correspond with local registers of dignified efficiency in communication. As in all languages, some sign elements are wellestablished, while others are more recent innovations. ${ }^{2}$

Despite the centrality of hand signs within Aboriginal community life, there has been relatively little written about them in comparison to Aboriginal spoken languages. One reason for this has to do with the history of linguistics, in which the study of written and oral languages has generally been prioritized over gesture systems and sign languages (Kendon 2004). In addition to the

2 More recent signs include pamarr (money), kitjikarra (cards), and motika (motor car) (4:305:07). Kids in particular tend to have a variety of novel signs around technologies, especially smart phones. 
ideological reasons for such discrepancies, there are also practical ones. While words of course lend themselves to written analysis, it is challenging to capture the gestures within this medium. ${ }^{3}$

Unlike static text, moving images are ideally suited to capture the corporeality of meaningful movement (MacDougall 2006). Indeed, the rise of video opened up an exciting new era of engaging gestures in Aboriginal Australian communities. As demonstrated by Margaret Carew and Jennifer Green (2015), video dictionaries provide a dynamic means for recording and disseminating hand signs, communicating not only the nuance of their usage, but also the users' embodied personalities. Their work emphasizes the central importance of collaborative engagement, and provides project outcomes requested by and useful for community-members, including edited footage on websites/archives and posters embedded with QR codes that link to short video clips.

Marumpu Wangka was one of the many Pilbara and Kimberley Aboriginal Media (PAKAM) projects that I worked on throughout my fieldwork. Managed by Neil Turner, PAKAM is an Indigenous-run and owned media organization centered in the coastal Kimberley pearling town of Broome. It serves as the organizational rebroadcasting hub for eight town stations and twelve Aboriginal community stations (including the one in Balgo). I had previously collaborated on larger PAKAM projects in Balgo beginning in 2013, including Tjawa Tjawa, a big-budget 2014 documentary film trip funded by NITV and Screen Australia. Such large projects included the Elders from Marumpu Wangka, as well as dozens of other community members travelling throughout the region in Toyota Land Cruisers, and included more than a week of driving, camping, and filming.

Marumpu Wangka - which translates from Kukatja to English as "hand talk" - was an unexpected outcome of several months of hanging out with women Elders at Kapululangu after these big film projects. During these months as a PAKAM media volunteer, I was involved in radio/video training, screening rough cuts of Tjawa Tjawa, and assisting on various films that community members were interested in making. Having known the Kapululangu Elders for years, I would spend long afternoons sitting around joking and chatting with them, often discussing the complex system of hand

3 There has been an increasing interest in ethnographic engagements with gesture in recent years (e.g., Covington-Ward 2016). 
signs. I had become interested in these during my first visit to Balgo, when I learned the most common signs. ${ }^{4}$ While hand signs are used throughout the community, these Elders seemed to have a special love for them. This is in part because, as some of the oldest people in the community, they fondly associated signs with their youth, before they came into the original Balgo mission (de Ishtar 2005). The Elders, myself, and Zohl de Ishtar-the Executive Director of Kapululangu — soon arrived at the idea of trying to film some of the signs, and began organizing and translating as many gestures as everyone could think of.

After weeks of discussing our potential video shoot, we were approaching the funeral for the daughter of Linda, one of the women Elders. During the time leading up to a funeral there is "sorry business," including weeks of public mourning. On the day before the funeral, I was spending time with the women when Linda suddenly proclaimed, "let's make the film now." I was hesitant and asked if maybe we should not worry about the hand sign video for a while. However, she and the other Elders were adamant and asserted, "no, now is the right time." With the benefit of hindsight, I think that part of why they wanted to film it then was to create a moment of levity during a difficult time of grief.

We all got into the Toyota Landcruiser and drove just a few minutes down the road from Kapululangu. We placed a few blankets on the side of the pindan track and clipped a radio mic to the back of Payi Payi's blue hat. Cross-legged, I operated the camera next to Zohl as we all sat around joking about signs. Having slowly developed this video concept together, this felt less like a film shoot and more like one more afternoon at the women's center. Indeed, more than anything, this video documents our established joking relationship, in which my repeated misunderstandings during this learning process were ripe for comedic banter, some of which did not make it into the final edit.

One particular moment stands out, in which I asked about the sign for what I thought meant "I'm confused." As I scratched my head and furrowed my brow, they genuinely were confused. They looked at each other as if to decide whether or not to respond, and then started to laugh and scratch their own heads in an exaggerated fashion. It turned out that I accidentally did the sign for "lice." In this and other moments I was reminded of the patience and good humor that the women expressed toward myself and others.

As the shoot continued, the three primary women Elders became increasingly expressive. Manaya particularly enjoyed acting out the scenarios, while Payi Payi and Linda were determined to get each one exactly right. Having only one camera, we discussed all the signs while shooting from the front, as well as again with the camera shooting the women from the side, to

4 These include the nganaku? (what?) and wiya (nothing) signs (o:18-o:33).

VIDEO JOURNAL OF EDUCATION AND PEDAGOGY (2O19) 1-10 
present the gestures in profile. This was especially important for signs that move away from the body going forward, such as marlu (kangaroo). ${ }^{5}$ We also attempted another shoot with five Elders (instead of the three). While more cinematic — with the community overlook in the background-it became clear that it was not the right moment, and we quickly decided to move on, as it was the ineffable feeling of lightness and comedy that made the other shoot, and thus the film, work.

Marumpu Wangka was streamed online through the Australian Broadcasting Corporation's "Mother Tongue" series on their ABC OPEN website, through the ever-supportive assistance of ABC Kimberley Producer Alex Smee. We were pleasantly surprised that the eight-minute film was viewed over 10,000 times and received a variety of awards, including the annual NITV Spirit Award, ${ }^{6}$ through which I facilitated a multi-camera, visual hand sign dictionary of over 300 signs and a TV half-hour featuring hand sign shorts, subtitled in English. ${ }^{7}$

Marumpu Wangka did well with diverse stakeholders and audiences, though not because of Western production values. The filming was quite basic, with a single camera and mic. Rather, it resonated because it represented a normal day in Balgo. As the Elders and Zohl were teaching me about the signs, so too were they intimately engaging with the audience through generous expressions of their personalities and everyday lives.

There was one moment in particular that evoked laughter in every audience I viewed it with, including screenings in Aboriginal communities, film festivals, and academic conferences. This was around the sign kitjikarra (cards). ${ }^{8}$ The Elders love to play cards, which is especially apparent in Manaya's embodied enactment. While Payi Payi and Linda gesture shuffling cards, Manaya dramatically acts out the process of dealing them, hiding her

$5 \quad(1: 21-1: 31)$.

6 In addition, Marumpu Wangka received the "People's Choice Award" runner-up at the 2015 ICTV Video Awards, and the "Best Webisode" and "Webisode Audience Choice Award" at the 2016 Intendence Film Festival. It was also selected for the 2016 Winda Film Festival (Imagine NATIVE Australia), the 2016 Harlem International Film Festival, and the 2016 Society for Visual Anthropology Film \& Media Festival.

7 The NITV Spirit Award was given to one remote community project per year by NITV in order to fund a half-hour of nationally broadcasted programing. One of two films making up the half-hour included Hand Talk Trilogy (2016), which consisted of three shorts, showing signs being used to describe cultural objects, the relationship between gestures and animal tracks, and a comedy skit through subtitled hand signs. The other film, Bush Hunt Hand Talk (2016), features Balgo women hunting for food while communicating with one another primarily through hand sings, subtitled into English. Taking place over a long day, the women plan and carry out a trip in the Kapululangu Land Cruiser, then return to eat bush food and kangaroo tails in the evening.

8 (4:40-4:57).

VIDEO JOURNAL OF EDUCATION AND PEDAGOGY (2O19) $\quad$ 1-10 
cards, and then pulling in her winnings. The fact that this moment produced a joyful audience reaction across such broad audiences is a testament to the ways in which these intimate gestures can connect with people from a diversity of backgrounds through embodied comedy (Carty and Musharbash 2008).

Hand sign videos serve as rich and dynamic pedagogical tools. This is true within communities, where the footage of hundreds of signs are organized in archives and the videos are regularly screened. These projects also serve as educational materials for broader audiences; the particular mix of including signs that many people associate with remote communities (such as boomerangs), and others that are less expected (such as playing cards), subtly encourages audiences to question their preconceived notions about Aboriginal communities. ${ }^{9}$

\section{$4 \quad$ Aboriginal Representation in Dangerous Times}

These are indeed dangerous times for Indigenous Australians. In addition to the recent attempts at defunding Aboriginal communities in Western Australia (as described earlier), the 2014 Indigenous Advancement Strategy has made deep cuts in Aboriginal community organizations and services over the past few years. This is part of a long-term trend toward defunding and delegitimizing remote Aboriginal communities. This trend includes other deficit-discourse policies, such as the Northern Territory National Emergency Response Act of 2007, commonly referred to as "the intervention," as well as Closing the Gap, a constellation of governmental policies formally established during that same era.

It might at first seem counterintuitive to suggest that intimate and humanizing videos have a meaningful role in addressing such legislation. However, these policies are based on decades of popularized representations of Aboriginal community life that center tropes of mythological Dreaming fantasies or futureless dystopias (Lempert 2018). Furthermore, unlike New Zealand, Canada, and the United States, Australia is one of the only first-world nations lacking treaties between Indigenous people and the state. While such treaties are certainly imperfect, they do provide at least some baseline level of

\footnotetext{
9 There are a variety of recent Indigenous Australian media that have presented complex depictions of Aboriginal communities across many genres (see Ginsburg 2012).
} 
sovereignty in comparison to Native Title. ${ }^{10}$ Thus, the fate of Aboriginal communities are particularly dependent on the popular political will of Australian citizens. Indeed, the mass defunding of Western Australian communities was halted largely due to protests in every major city in the continent.

At the same time, there is an abundance of Indigenous media in Australia, including two dedicated national networks (NITV and Indigenous Community Television), the Indigenous unit at the Australian Broadcasting Corporation (Australia's flagship public service broadcaster), and the Indigenous Department of Screen Australia that supports feature film production, as well as a variety of regional TV and radio stations. In the Kimberley, these include PAKAM, Goolarri Media Enterprises, Wawili Pitjas, and PRK Radio, just to name a few. Indeed, there are now unprecedented opportunities for circulating Indigenous media, including networks that broadcast into virtually every Australian household. The lack of treaties and the abundance of broadcasters contributes to the present context in which Indigenous Australian media have an unusually large potential influence on policies of justice.

Hand sign videos are one way of gesturing across settler divides in Australia. In Marumpu Wangka we had the rare luxury of proceeding through an organic and emergent process. Indeed, the women expressed excitement at having the freedom to work on projects beyond what they know from experience that outsiders want to fund and see, especially those including Elders, who have been too-often represented one-dimensionally as "precontact." These are indeed strong Law bosses (i.e., spiritual women), but they are not always serious while painting, singing, and/or dancing, as represented in most of their video depictions. Like Elders everywhere, they are charming, hilarious, grumpy, and most importantly, complicated. Thus, as you can see in the video, hand signs are not only a way of communicating information, but also serve as a full-bodied system for expressing the nuance, humor, and individuality embedded within everyday Aboriginal community life.

10 The 1993 Native Title Act was passed following the landmark 1992 Mabo v. Queensland case. Native Title provided a new legal foundation for Aboriginal land rights. This decision made pastoral lease holders particularly concerned about how this would impact their interests. The 1996 Wik Peoples v. The State of Queensland case settled this, declaring that Native Title could indeed coexist with pastoral leases. The conservative Liberal government led by John Howard responded to this decision by passing the 1998 Native Title Amendment Act, which heavily curtailed the scope and power of Native Title and represented a significant set-back for Aboriginal land rights (Bauman and Glick 2012).

VIDEO JOURNAL OF EDUCATION AND PEDAGOGY (2O19) $\quad \mathbf{1 - 1 0}$ 


\section{Acknowledgements}

I would like to thank, first and foremost, the collaborators on this film, including Mark Moora, Payi Payi Sunfly Napangardi, Linda Charmawina Napangardi, Manaya Sarah Daniels Napanangka, Mayan Kathleen Padoon Napanangka, Maudi Mandigalli Napananga, Mark Moora and Zohl de Ishtar. It would not have been possible without the tireless and cheerful support of PAKAM manager Neil Turner, as well as ABC Kimberley Producer Alex Smee. I am thankful for the helpful feedback in thinking about Aboriginal hand signs from Jennifer Green and Adam Kendon. I deeply appreciate the support by the Nulungu Research Institute, the Wenner-Gren Foundation for Anthropological Research, the Fulbright IIE US Scholar Program, the Lois Roth Endowment, the Andrew W. Mellon Foundation, and the American Council of Learned Societies.

\section{References}

Bauman, Toni, and Lydia Glick, eds. 2012. The Limits of Change: Mabo and Native Title 20 Years on. Canberra: AIATSIS Research Publications.

Carew, Margaret, and Jennifer Green. 2015. Making an online dictionary for Central Australian sign languages. International Journal of Learning in Social Contexts 16:40-54.

Carty, John, and Yasmine Musharbash. 2008. You've Got to be Joking: Asserting the Analytical Value of Humour and Laughter in Contemporary Anthropology. Anthropological Forum 18(3):209-217.

Covington-Ward, Yolanda. 2016. Gesture and Power: Religion, Nationalism, and Everyday Performance in Congo. Durham: Duke University Press.

de Ishtar, Zohl. 2005. Holding Yawulyu: White Culture and Black Women's Law. North Geelong: Spinifex Press.

Ginsburg, Faye. 2012. Australia's Indigenous New Wave: Future Imaginaries in Recent Aboriginal Feature Films. Adrian Gerbrands Annual Lecture, Leiden.

Kendon, Adam. 1988. Sign Languages of Aboriginal Australia: Cultural, Semiotic and Communicative Perspectives. Cambridge: Cambridge University Press.

Kendon, Adam. 1997. Gesture. Annual Review of Anthropology 26(1):109-128.

Kendon, Adam. 2004. Gesture: Visible Action as Utterance. Cambridge: Cambridge University Press.

Lempert, William. 2018. Generative Hope in the Postapocalyptic Present. Cultural Anthropology. 33(2):202-212. 
Lempert, William and Zohl de Ishtar. 2015. PAKAM / ABC OPEN. 8 min. https://vimeo.com/132209310.

MacDougall, David. 20o6. The Corporeal Image: Film, Ethnography, and the Senses. Princeton: Princeton University Press. 